\title{
Effects of Corn Particle Size and Physical Form of the Diet on the Gastrointestinal Structures of Broiler Chickens
}

Author(s)

Dahlke $F^{1}$

Ribeiro $\mathrm{AML}^{2}$

Kessler $\mathrm{AM}^{2}$

Lima $A R^{2}$

Maiorka $\mathrm{A}^{3}$

1-FCAV / UNESP, Jaboticabal - SP - Brasil

2-Depto. de Zootecnia - Faculdade de Agronomia/UFRGS, Porto Alegre - RS - Brasil

3. Depto. de Zootecnia - Universidade Federal do Paraná, Curitiba - PR - Brasil

Mail Address

Fabiano Dahlke

Depto. de Morfologia eFisiologiaAnimal - FCAV/NNESP Via de Acesso Profo Paulo Donato Castellane, Km5 14884-900 - Jaboticabal - SP - Brazil

E-mail: fdahlke@fcav.unesp.br

\section{ABSTRACT}

The objective of this experiment was to investigate the effects of different particle sizes, expressed as Geometric M ean Diameter (GMD) of corn $(0.336 \mathrm{~mm}, 0.585 \mathrm{~mm}, 0.856 \mathrm{~mm}$ and $1.12 \mathrm{~mm})$ of mash and pelleted broiler chicken diets on the weight of the gizzard, duodenum and jejunum+ileum; on the $\mathrm{pH}$ of the gizzard and small intestine and on the characteristics of the duodenal mucous layer (number and height of villi and crypt depth) in 42-day-old broilers. The physical form and the particle size of the diet had no significant effect on gizzard and intestine $\mathrm{pH}(\mathrm{p}>0.05)$. A greater gizzard weight was seen in the birds receiving pelleted diet and particle size of $0.336 \mathrm{~mm}(p \leq 0.008)$. How ever, for the particle sizes of 0.856 and $1.12 \mathrm{~mm}$, a greater weight was found in birds that received mash diet $(p \leq 0.039$ and $p \leq 0.006$, respectively). Also, gizzard weight was greater with increasing corn GMD independent of the physical form of the diet. In the mash diet, the increase in particle size promoted a quadratic response in the weight of duodenum and jejunum + ileum. The pelleted diet promoted a greater number of villi per transverse duodenum cut $(p \leq 0.007)$ and greater crypt depth $(p<0.05)$. As the particle size increased, there was a linear increase of villus height and crypt depth in the duodenum, irrespective of the physical form of the diet.

\section{INTRODUCTION}

Particles size of the diet seems to have great importance in regulating the intake in broiler chickens, that show preference for diets containing larger particles instead of those finely ground (Nir et al., 1994a). Birds have difficulty in eating particles that are bigger or much smaller than the size of the beak (M oran, 1982). Nir et al. (1995) suggested that particle digestion within the proximal small intestine is slower when particles are bigger, resulting in more peristaltic movements and maybe a better utilization of the nutrients. Thus, the consumption of diets with different characteristics may not be similar and may have a direct effect on the morphological structure of the digestive system of the birds, such that any alteration in the structure of the feed might have a significant effect on performance by restricting or making some nutrients unavailable (M acari et al., 1994). For example, birds that eat fiber and/or coarse food tend to have a longer gastrintestinal tract (Denbow, 2000). On the other hand, both gizzard atrophy (Nir et al., 1994a; Nir et al., 1995; Magro, 1999) and a discrete intestinal hypertrophy (Nir et al., 1994a) have been observed when finely ground food was fed to the birds.

Pelleting also seems to directly affect the gastrintestinal tract. Nir et al. (1995) observed that pelleting resulted in a decrease in the weight and contents of the proventriculus, gizzard and small intestine, as well 
as a decrease in the small intestine length (Nir et al., 1994a). Nevertheless, no change of pH was reported in these studies.

The present study investigated the potential influence of corn particle size and diet physical form on changes in the digestive system in broiler chickens, such as the weight of the gizzard, duodenum and jejunum + ileum; the $\mathrm{pH}$ of the gizzard and small intestine; number and height of villi and crypt depth in duodenal mucosa.

\section{MATERIAL AND METHODS}

Two hundred Ross male broiler chickens were reared from 21 to 42 days of age, according to general commercial husbandry. Birds were reared in battery cages measuring $0.43 \times 0.95 \times 0.35 \mathrm{~m}$ and equipped with a trough feeder and drinker. Water and feed were given ad libitum and birds had a continuous light. A completely randomized experimental design was used, with 8 treatments, 5 repetitions per treatment and 5 birds per repetition. Treatments were: $T 1: 0.336 \mathrm{~mm}$, T2: $0.585 \mathrm{~mm}, \mathrm{~T} 3: 0.856 \mathrm{~mm}$ and T4: $1.12 \mathrm{~mm}$ of geometric mean diameter (GMD) given as a mash diet; T5, T6, T7 and T8 had the same particle sizes and the food was pelleted. The different corn particle sizes were obtained at the feed mill using a hammermill, and screens of $12 \mathrm{~mm}, 8 \mathrm{~mm}, 2.5 \mathrm{~mm}$ and $0.8 \mathrm{~mm}$. GMD was determined according to Zanotto \& Bellaver (1996). Experimental diets had the same ingredient and nutrient composition, with $20 \%$ crude protein (CP), $3.150 \mathrm{kcal}$ of metabolizable energy (ME)/ $/ \mathrm{kg}, 0.9 \% \mathrm{Ca}, 0.35 \% \mathrm{P}$, $0.18 \% \mathrm{Na}, 1 \%$ Lysine and $0.72 \%$ Methionine+Cystine. Hot pelleting was done using maximal vapor injection, approximate conditioning time of 15 minutes, and temperature of $70^{\circ} \mathrm{C}$. At 42 days of age, the birds were individually weighed and the mean body weight of each repetition was calculated. Two birds with body weight similar to the mean body weight of the repetition were sacrificed per repetition by cervical dislocation, and the gizzard, duodenum and jejunum+ileum were weighed. The contents of the gizzard and small intestine were collected, homogenized with deionized water and $\mathrm{pH}$ was measured using a DM 20 DIGIMED pH meter. Fragments of approximately $2 \mathrm{~cm}$ were also collected from the small intestine (duodenum) and fixed in 10\% buffered formalin $(100 \mathrm{~mL}$ of $40 \%$ formaldehyde, $4 \mathrm{~g}$ of monobasic sodium phosphate, $6.5 \mathrm{~g}$ of dibasic sodium phosphate and $900 \mathrm{~mL}$ of distilled water). The fragments were dehydrated by transferring through a series of alcohols with increasing concentrations, placed into xylol and embedded in paraffin. A microtome was used to make 14 cuts with $5 \mu$, which were placed on glass slides. The cuts were stained with periodic acid-Schift (PAS) stain and covered with coverslips. Villus number, villus height and crypt depth were evaluated by transverse duodenum cut (14 cuts with 5 micrometers). Data were submitted to analysis of variance, contrast analysis and regression analysis at a 5\% significance level.

\section{RESULTS AND DISCUSSION}

The pelleted diet did not affect significantly the $\mathrm{pH}$ in the gizzard and the intestine ( $p>0.05)$ (Table 1). Similar data were found by Nir et al. (1994a) and Nir et al. (1995), who reported that the pelleting process reduced proventriculus and gizzard weight, as well as their contents, without changing the $\mathrm{pH}$ of these segments. Our findings showed that particle size also had no effect on proventriculus and gizzard weight ( $p>0.05$ ) and the regression analysis confirmed these results. These data are different from those reported by Nir et al. (1994b), who showed a negative relationship between particle size and $\mathrm{pH}$, as particle size decreased there was an increase in gastric $\mathrm{pH}$. Nevertheless, these authors used particle sizes within a different range from the range used in the present study (0.67 to $2.1 \mathrm{~mm})$, which might explain the diverging results.

There was a higher relative weight (grams per kg of live weight) of the gizzard in the birds fed pelleted diet with particle size of $0.336 \mathrm{~mm}$. A harder pellet produced by a finely ground corn might be the reason for this result. Nevertheless, particle sizes of 0.856 and $1.12 \mathrm{~mm}$ show ed a higher gizzard weight when birds were given the mash diet $(p \leq 0.039$ and $p \leq 0.006$, respectively).

Gizzard weight generally increased with the increase in corn GMD, independently which was the physical form of the diet. This observation corroborates findings from Olver \& Jonker (1997) and Nir et al. (1994b), who also showed a direct relationship between the particle size of the ingredients or diet and the morphology of the digestive system. Nir et al (1994b) observed that the gizzard weight in 7-day-old chicks fed coarse and medium particles was 26 to $41 \%$ higher than in chicks fed fine particles, respectively. Nir et al. (1995) found similar results when studying the effect of grinding wheat and sorghum with a hammer or a roll. There was a reduction in gizzard weight when a hammermill was used and smaller particle sizes were produced and given to the birds.

A significant interaction $(p<0.001$ ) between physical form and particle size was seen in the small intestine, 
Table 1 - Gizzard and intestine pH and weight of gizzard, duodenum and jejunum+ileum in broiler chickens at 42 days of age fed mash or pelleted diets with different particle sizes.

\begin{tabular}{|c|c|c|c|c|c|}
\hline \multirow[t]{2}{*}{ Treatments } & \multicolumn{2}{|c|}{ pH } & \multicolumn{3}{|c|}{ Weight (g) } \\
\hline & Gizzard & Intestine & Gizzard & Duodenum & Jejunum+ileum \\
\hline Mash- $0.336 \mathrm{~mm}$ & $3.82 a^{1}$ & $6.69 \mathrm{~b}$ & $20.05 \mathrm{e}$ & $8.76 \mathrm{~b}$ & $27.35 \mathrm{~b}$ \\
\hline Pelleted $0.336 \mathrm{~mm}$ & $3.77 \mathrm{a}$ & $6.82 a b$ & $25.82 \mathrm{de}$ & $15.48 \mathrm{a}$ & $50.26 a$ \\
\hline Mash- $0.585 \mathrm{~mm}$ & $3.65 a b$ & $6.87 a b$ & $29.52 \mathrm{~cd}$ & $13.89 a$ & 43.77 a \\
\hline Pelleted $-0.585 \mathrm{~mm}$ & $3.88 \mathrm{a}$ & $6.88 a b$ & $30.58 \mathrm{bcd}$ & $14.28 \mathrm{a}$ & $48.46 \mathrm{a}$ \\
\hline Mash- $0.856 \mathrm{~mm}$ & $3.20 a b c$ & $6.69 \mathrm{~b}$ & $36.03 a b$ & $12.48 \mathrm{a}$ & $42.56 \mathrm{a}$ \\
\hline Pelleted $-0.856 \mathrm{~mm}$ & $3.14 a b c$ & $7.30 \mathrm{a}$ & $32.62 b c$ & 13.77 a & 46.30 a \\
\hline Mash-1.12mm & $2.87 \mathrm{c}$ & $6.97 a b$ & 41.56 a & $13.84 \mathrm{a}$ & 41.90 a \\
\hline Pelleted-1.12mm & $2.69 b c$ & $6.89 a b$ & $37.71 \mathrm{ab}$ & $13.40 \mathrm{a}$ & 45.98 a \\
\hline CV \% & 23.67 & 5.78 & 16.37 & 17.93 & 18.68 \\
\hline \multicolumn{6}{|c|}{ Main source } \\
\hline Pelleted & 3.87 & 6.97 & 31.68 & 14.34 & 47.76 \\
\hline Mash & 3.38 & 6.80 & 32.04 & 12.13 & 38.89 \\
\hline $0.336 \mathrm{~mm}$ & 3.78 & 6.75 & 22.93 & 12.11 & 38.81 \\
\hline $0.585 \mathrm{~mm}$ & 3.77 & 6.87 & 30.05 & 14.08 & 46.11 \\
\hline $0.856 \mathrm{~mm}$ & 3.22 & 6.95 & 34.82 & 13.12 & 44.46 \\
\hline $1.12 \mathrm{~mm}$ & 2.78 & 6.93 & 39.63 & 13.62 & 43.94 \\
\hline \multicolumn{6}{|c|}{ Probability } \\
\hline Physical Form (PF) & 0.268 & 0.057 & 0.758 & $<0.001$ & $<0.001$ \\
\hline Particle Size (PS) & 0.692 & 0.279 & $<0.001$ & 0.052 & 0.033 \\
\hline PF $\times$ PS & 0.371 & 0.362 & $<0.001$ & $<0.001$ & 0.001 \\
\hline \multicolumn{6}{|c|}{ Contrast } \\
\hline $0.336 \mathrm{Mas}^{2} \times 0.336 \mathrm{Pel}$ & & 0.008 & 0.001 & 0.001 & \\
\hline $0.585 \mathrm{M}$ as $\times 0.585 \mathrm{Pel}$ & & 0.622 & 0.66 & 0.22 & \\
\hline $0.856 \mathrm{M}$ as $\times 0.856 \mathrm{Pel}$ & & 0.039 & 0.74 & 0.29 & \\
\hline 1.12 Mas $\times 1.12$ Pel & & 0.006 & 0.59 & 0.25 & \\
\hline
\end{tabular}

1 - M eans with different letters in the same column are statistically different $(p<0.05)$ by Tukey's test.

2 - Mas=mash, Pel=pelleted.

showing that the mash diet (GMD of $0.336 \mathrm{~mm}$ ) promoted smaller duodenum and jejunum+ileum weight when compared to the other particle sizes. This effect was not seen when the same particle size was used in pelleted diets. This variable show ed no difference between mash or pelleted diets for the other GMDs. Particle size had a quadratic response on duodenum and jejunum + ileum weight when mash diet was given (Table 2), as well as when particle size was evaluated independently of the physical form. A previous work reported no difference in the weight of these organs with particle sizes of 0.6 to $2.17 \mathrm{~mm}$ (Nir, et al., 1995). It is worth noting, however, that the smaller particle size $(0.336 \mathrm{~nm})$ in the mash ration, that influenced the results presented here, was not used by Nir et al., (1995).

As shown in Table 3, the pelleted diet promoted a higher number of villi per transversal duodenum cut when compared to the mash diet $(p \leq 0.007)$, but there 
Table 2 - Polinomial regression analysis of gizzard weight, duodenum weight, jejunum +ileum weight; gizzard pH and intestine $\mathrm{pH}$ in 42-days-old broiler chickens fed mash or pelleted diets with different particle sizes.

\begin{tabular}{|c|c|c|c|c|}
\hline Variable & Response & Mash & Pelleted & Particle Size \\
\hline \multirow[t]{4}{*}{ Gizzard pH } & Regression & & & \\
\hline & Probability & n. s. ${ }^{1 *}$ & n. s.* & n. s.* \\
\hline & Equation & & & \\
\hline & $R^{2}$ & & & \\
\hline \multirow[t]{4}{*}{ Intestine $\mathrm{pH}$} & Regression & & & \\
\hline & Probability & n. s.* & n. s.* & n. s.* \\
\hline & Equation & & & \\
\hline & $\mathrm{R}^{2}$ & & & \\
\hline \multirow[t]{4}{*}{ Gizzard weight } & Regression & Linear & Linear & Linear \\
\hline & Probability & 0.0001 & 0.003 & 0.0001 \\
\hline & Equation & $Y=10.93+28.79 X$ & $Y=20.64+15.09 X$ & $Y=15.81+21.93 X$ \\
\hline & $R^{2}$ & 0.97 & 0.97 & 0.98 \\
\hline \multirow[t]{4}{*}{ Duodenum weight } & Regression & Quadratic & & \\
\hline & Probability & 0.007 & n. s.* & n. s.* \\
\hline & Equation & $Y=0.25+30.94 X-17.56 X^{2}$ & & \\
\hline & $\mathrm{R}^{2}$ & 0.70 & & \\
\hline \multirow{4}{*}{$\begin{array}{l}\text { Jejunum + } \\
\text { ileum weight }\end{array}$} & Regression & Quadratic & & Quadratic \\
\hline & Probability & 0.001 & n. s.* & 0.034 \\
\hline & Equation & $Y=-7.98+125.46 X-73.32 X^{2}$ & & $Y=23.84+54.22 X-32.98 X^{2}$ \\
\hline & $R^{2}$ & 0.86 & & 0.77 \\
\hline
\end{tabular}

1 - ns: non significant polynomial regression $(p>0.05)$. 
Table 3 - Villus number, villus height and crypt depth in the medial portion of the duodenum in 42-days-old broiler chickens fed mash and pelleted diets with different particle sizes.

\begin{tabular}{|c|c|c|c|}
\hline Treatments & $\begin{array}{c}\text { Villus number } \\
\text { (villi/transversal intestine cut) }\end{array}$ & Villus height $(\mu \mathrm{m})$ & Crypt depth $(\mu \mathrm{m})$ \\
\hline Mash-0.336mm & 51 & 1509 & 137 \\
\hline Pelleted $0.336 \mathrm{~mm}$ & 52 & 1529 & 191 \\
\hline Mash- $0.585 \mathrm{~mm}$ & 46 & 1744 & 184 \\
\hline Pelleted $-0.585 \mathrm{~mm}$ & 56 & 1534 & 229 \\
\hline Mash- $0.856 \mathrm{~mm}$ & 51 & 1811 & 228 \\
\hline Pelleted $-0.856 \mathrm{~mm}$ & 54 & 1620 & 204 \\
\hline Mash-1.12mm & 50 & 1831 & 200 \\
\hline Pelleted-1.12mm & 53 & 1995 & 252 \\
\hline CV \% & 10.28 & 15.93 & 35.00 \\
\hline \multicolumn{4}{|c|}{ Main source } \\
\hline Pelleted & 53 & 1669 & 219 \\
\hline Mash & 50 & 1724 & 187 \\
\hline $0.336 \mathrm{~mm}$ & 51 & 1519 & 164 \\
\hline $0.585 \mathrm{~mm}$ & 52 & 1639 & 207 \\
\hline $0.856 \mathrm{~mm}$ & 52 & 1715 & 216 \\
\hline $1.112 \mathrm{~mm}$ & 51 & 1913 & 226 \\
\hline \multicolumn{4}{|c|}{ Probability } \\
\hline Physical form (PF) & 0.007 & 0.624 & 0.048 \\
\hline Particle size (PS) & 0.804 & 0.001 & 0.038 \\
\hline $\mathrm{PF} \times \mathrm{PS}$ & 0.553 & 0.090 & 0.261 \\
\hline
\end{tabular}


Table 4 - Polinomial regression analysis of villus number, villus height and crypt depth in 42-days-old broiler chickens fed mash and pelleted diets with different particle sizes.

\begin{tabular}{|c|c|c|c|c|}
\hline Variable & Response & Mash & Pelleted & Particle Size \\
\hline \multirow[t]{4}{*}{ Villus number } & Regression & & & \\
\hline & Probability & n. s. ${ }^{1 *}$ & n. s.* & n. s.* \\
\hline & Equation & & & \\
\hline & $R^{2}$ & & & \\
\hline \multirow[t]{4}{*}{ Villus height } & Regression & & & Linear \\
\hline & Probability & n. s.* & n. s.* & 0.00008 \\
\hline & Equation & & & $Y=1326.21+506.69 \mathrm{X}$ \\
\hline & $\mathrm{R}^{2}$ & & & 0.98 \\
\hline \multirow[t]{4}{*}{ Crypt depth } & Regression & & & Linear \\
\hline & Probability & n. s.* & n. s.* & 0.0008 \\
\hline & Equation & & & $Y=147.31+76.92 X$ \\
\hline & $R^{2}$ & & & 0.95 \\
\hline
\end{tabular}

1 - ns: non significant polynomial regression ( $p>0.05)$.

was no influence of the particle size on this variable, contradicting data from Nir et al. (1995) and Nir et al. (1994a).

Diet form did not promote an alteration in villus height in the duodenum, but particle size influenced this variable $(p<0.001)$. Polinomial regression analysis showed a linear response $(p<0.001)$, that is, the increase in particle size increased villus height (Table 4). These data corroborate the idea of high susceptibility of alterations in the structure of the intestinal mucosa due to the type of ingested food (Sturkie, 2000). Ingredients with larger particle size have lower rate of passage through the gastrintestinal tract (Warner, 1981), which results in a greater contact between the food and the intestinal mucosa, increasing villus height.

Physical form of the diet influenced crypt depth in the duodenum, which was higher in the birds given pelleted diet ( $p \leq 0.048$ ). The explanation for such finding is not clear, since the pellet dissolves within the proventriculus (Nir et al., 1994c), and thus it was not expected that physical form of the diet would have any effect in this portion of the gastrintestinal tract. The high coefficient of variation ( $35 \%$ ) of this analysis advises for extra care during data interpretation. Crypt depth was also influenced by particle size ( $p \leq 0.038)$; larger particles promoted deeper crypts. These data are in accordance with the studies that show that the type and the size of the food that is ingested may change the characteristics of the intestinal mucosa, causing ulcerations, haemorrhages or affecting villus height and crypt depth (Franti et al., 1972; Harry et al., 1975); Dibner et al., 1996).

\section{CONCLUSIONS}

The finding of this study showed that, gizzard weight increased linearly with the increase in particle size, in both mash and pelleted diets. On the other hand, proventriculus $\mathrm{pH}$ and intestinal $\mathrm{pH}$ were not affected by different particle sizes in the diet. Pelleted diets increased the number of duodenum villi, whereas the increase in the particle size promoted deeper crypt and higher duodenum villi.

\section{REFERENCES}

Denbow DM. Gastrointestinal anatomy and physiology.In: GC Whittow (editor). Sturkie's Avian Physiology. Academic Press, London. 2000. p. 299-325.

Dibner JJ, Kitchell ML, Atwell CA, IVEY, FJ. The effect of dietary ingredients and age on the microscopic structure of the gastrointestinal tract in poultry. Journal of Applied Poultry Research 1996; 5:71-77.

Franti CE, Julian LM, Adler HE, Wiggins A.D. Antibiotic growth promotion: Effects of zinc bacitracin and oxytetracycline on the digestive, cicrculatory, and excretory systems of New Hampshire cockerels. Poultry Science 1972; 51:1137-1145. 
Harry EG, Tucker JF, Laersen-Jones AP. The role of histamine and fish meal in the incidence of gizzard erosion and proventricular abnormalities in the fowl. British Poultry Science 1975; 6: 69-78.

Macari M , Furlan RL, Gonzales E. Fisiologia aviária aplicada a frangos de corte. Jaboticabal: Funep/Unesp,1994. 294p.

Magro N. Variação da granulometria das rações em frangos de corte machos, de 21 aos 42 dias de idade.[Dissertação]. Universidade Federal do Rio Grande do Sul. Porto Alegre (RS). 1999.

Moran Jr ET. Comparative nutrition of the fowl and swine. In: The ET M oran (editor). Gastrointestinal Systems. Guelph: University of Guelph, 1982.p. 250.

Nir IG, Shefet $Y$, Aroni G. Effect of particle size on performance. 1.Corn. Poultry Science 1994a; 73: 45-49.

Nir I, Hillel R, Shefet G, Nitsan Z. Effect of grain particle size on performance. 2. Grain texture interactions. Poultry Science 1994b; 73:781-791.

Nir I, Twina Y, Grossman E, Nitsan Z. Quantitative effects of pelleting on performance, gastrointestinal tract and behavior of meat-type chicken. British Poultry Science 1994c; 35:589-602.

Nir I, Hillel R, Ptichi I. Effect of particle size on performance: 3. Grinding pelleting interactions. Poultry Science 1995; 74:771-783.

Olver MD, Jonker A. Effect of choice feeding on the performance of broilers. British Poultry Science 1997; 35:571-576.

Warner $\mathrm{ACl}$. Rate of passage of digesta through the gut of mammals and birds. Nutrition Abstracts and Reviews 1981 (Series B); $51: 789-820$.

Zanotto DL, Bellaver C. M étodo de determinação da granulometria de ingredientes para uso de rações de suínos e aves. Concórdia: Embrapa-CNPSA, 1996. (Embrapa-CNPSA. Comunicado técnico, 215). 1996. $5 p$. 